inter- reader reliability [(individual ICC $=0.867$ (IC95\% 0.786-0.934); average ICC $=0.997($ IC95\% 0.995-0.999)].

When comparing high with low experience sonographers, there was no significant differences in intra-class correlation coefficient. However, there was a greater variation between the means among low experience readers (13 to 22) and higher experience sonographers (14-18) (Figure 1).

Conclusions: US reliability is related to sonographer expertise and experience. Acknowledgements: Edith Alarcón, Lucio Ventura, Walter J. Spindler, Christina Hernandez-Diaz, Javier Rosa, Santiago Ruta, Mara Guinsburg, Gustavo Rodriguez Gil, Cecilia Urquiola, Guillermo Py, Magalí Alva, Patricio Tate, Carmen Cerón, Lida Santiago, Ana Laura Alvarez del Castillo Araujo, Maria Jezabel Haye Salinas, Erika Catay, Maximiliano Bravo, Johana Zacariaz, Clarisa Sandobal, Gonzalo Pacheco, Mariana Benegas, David Navarta, Verónica Arturi, Ana Bertoli, Marcelo Audisio, Carlos Pineda, Natalia Estrella, Carla Airoldi, Paula Kohan, María Julia Santa Cruz, Lina Saldarriaga Rivera, Romulo Wong, Ignacio Carrillo, Hugo Najera, Julio García, Daniele Freitas Pereir, Fernanda Athayde Cardoso Linhares, José Alexandre Mendonça, Maritza Quintero, Anthony M. Reginato, Eliana Natalí Ayala Ledesma, Lorena Urioste, Eugenio De Miquel, María Soledad Gálvez Elkin, Carla Saucedo, Josefina Marin, Rodolfo Arape, Marwin Gutierrez. Disclosure of Interest: None declared

DOI: 10.1136/annrheumdis-2017-eular.5870

\section{AB1061 THE HIGH DOSES GOLIMUMAB BRING BETTER SUPPRESSION OF ULTRASONOGRAPHIC SYNOVIAL INFLAMMATION IN PATIENTS WITH RHEUMATOID ARTHRITIS?}

T. Okano $^{1}$, K. Inui ${ }^{1}$, Y. Sugioka ${ }^{2}$, K. Mamoto $^{1}$, T. Koike ${ }^{2,3}$, H. Nakamura $^{1}$. ${ }^{1}$ Department of Orhopedic surgery; ${ }^{2}$ Center for Senile Degenerative Disorders (CSDD), Osaka City University Graduate School of Medicine, Osaka; ${ }^{3}$ Search Institute for Bone and Arthritis Disease (SINBAD), Shirahama Foundation for Health and Welfare, Wakayama, Japan

Background: Biologic diseasemodifying antirheumatic drugs (bDMARDs) that target cytokines and cytokine receptors such as tumor necrosis factor (TNF)alpha and interleukin (IL)6 have been established as a standard therapy of rheumatoid arthritis (RA) for patients with conventional systemic DMARDs, such as methotrexate (MTX), resistant disease. Golimumab, one of the bDMARDs, is an antibody targeting to TNF-alpha. In Japan, we can choose the dose of golimumab $50 \mathrm{mg}$ or $100 \mathrm{mg}$ according to the disease activity. Recent advance of ultrasound (US) equipment allows obtaining high-quality gray-scale (GS) imaging and sensitive power Doppler (PD) assessment, especially at small joints of the hands and feet. To date, US is the most sensitive imaging modality available in daily rheumatology practice for the assessment of residual synovitis.

Objectives: The aim of this study was to compare the ultrasound findings between patients with rheumatoid arthritis (RA) treated by golimumab $100 \mathrm{mg}$ and 50mg.

Methods: Patients with RA treated by golimumab were consecutively included. Ultrasound examination was performed at 52 synovial sites, bilateral first to fifth MCP, first IP and second to fifth PIP joints, first to fifth flexor tendon and wrists, 2nd and 6th compartment of extensor tendons and first to fifth MTP joints, by using HI VISION Ascendus (Hitachi Medical Corporation, Japan) with a multifrequency linear transducer $(18-6 \mathrm{MHz})$. The GS and PD signals were scored in each synovial site using a semi-quantitative scale from 0 to 3 .

Results: Fifty-five patients with RA (46 female, mean age: $64.2 \pm 12.1$ years) were included and analyzed. In comparison between the dose of Golimumab at the time of ultrasound examination, disease activity (DAS28-CRP) was significantly higher in 100mg group (100mg, $n=15: 3.6 \pm 1.0,50 \mathrm{mg}, n=40: 2.3 \pm 0.9 ; p<0.001$ ), but ultrasound findings were not significantly different between golimumab $100 \mathrm{mg}$ and $50 \mathrm{mg}$ groups. In patients achieving remission, ultrasound findings were not different between $100 \mathrm{mg}$ started and $50 \mathrm{mg}$ started groups.

Table 1. The comparison between golimumab $100 \mathrm{mg}$ and $50 \mathrm{mg}$ RA patients at the time of ultrasound examination

\begin{tabular}{lccc} 
& Golimumab $100 \mathrm{mg}(\mathrm{n}=15)$ Golimumab 50mg $(\mathrm{n}=40)$ & $P$ value \\
\hline Age (years old) & $60.3 \pm 12.2$ & $65.6 \pm 12.0$ & 0.161 \\
Disease duration (years) & $17.5 \pm 9.6$ & $14.2 \pm 9.5$ & 0.263 \\
Duration of golimumab use (years) & $1.8 \pm 0.9$ & $2.1 \pm 1.5$ & 0.542 \\
DAS28-CRP & $3.6 \pm 1.0$ & $2.3 \pm 0.9$ & $<0.001$ \\
SDAI & $14.0 \pm 6.9$ & $5.7 \pm 5.0$ & $<0.001$ \\
Total GSUS score & $16.9 \pm 12.6$ & $14.8 \pm 12.7$ & 0.572 \\
Total PDUS score & $11.3 \pm 9.07$ & $6.5 \pm 6.0$ & 0.076 \\
Maximum PDUS grade & $2.0 \pm 1.0$ & $1.6 \pm 0.8$ & 0.207 \\
\hline
\end{tabular}

Conclusions: Even patients have high disease activity, golimumab 100mg suppress the synovitis and tenosynovitis very well. In the condition where disease activity was sufficiently controlled, there was no difference in the synovitis findings of ultrasound at the dose of golimumab.

Acknowledgements: We wish to thank Setsuko Takeda, Ayumi Hashimoto, Emi Yamashita, Rika Morinaka, Hatsue Ueda and Tomomi Iwahashi for their special efforts as a sonographer and collecting data.

Disclosure of Interest: None declared

DOI: 10.1136/annrheumdis-2017-eular.1451

\section{AB1062 PATTERNS OF MUSCULOSKELETAL SYSTEM INVOLVEMENT IN PATIENTS WITH TYPE I AND TYPE II DIABETES MELLITUS}

T.I. Adrosy, M.I. Hanafy, H.S. Hamoud, A.A. Negm. Rheumatology Department, Faculty of Medicine, Al-Azhar Univerist, Cairo, Egypt

Background: Diabetes mellitus (DM) is a chronic disease, no known cure except in very specific situations. Musculoskeletal Utrasonography (MSUS) has a great sensitivity that can help clinical examination for the detection of peripheral enthesitis associated with DM

Objectives: To study the different patterns of musculoskeletal (MSK) system affection in both types of diabetes mellitus (DM).

Methods: We performed a retrospective single-center study on sixty five patients during the period from May 2014 to February 2015, to evaluate MSK manifestations in diabetic patients at Sayyed Galal University Hospital, Cairo, Egypt. Patients were identified as diabetics based on Diagnosis and Classification of Diabetes Mellitus diagnostic criteria (1997) (1). Clinical data, laboratory investigations, X-ray, musculoskeletal ultrasonography (MSUS) (2) and Bone mineral density was measured using Dual energy X-ray absorptiometry (DEXA) scan (3) were all collected from all patients.

Results: We included 65 diabetic patients; of these 21 patients (32.31\%) had type I diabetes while 44 patients $(67.69 \%)$ had type II diabetes. Age in type I was $24.5 \pm 10.5$ years while in type II was $50.1 \pm 8.44$ years $(P=0.001)$. DM type II showed higher BMI $(P=0.001)$, fatigue $(P=0.005)$, shoulder periarthritis (frozen shoulder) $(P=0.034)$, knee osteoarthritis $(P=0.002)$, cheiroarthropathy $(P=0.016)$, anserine bursitis $(P=0.001)$ and plantar fasciitis $(P=0.003)$ than type I. Osteoporosis was found in both types but type II showed more prevalence $13 / 44$ patients $(29.5 \%)$ while type I showed only $3 / 21(14.2 \%)$. No statistically significant difference between both groups as regard t-score in the three sites. MSUS showed increased prevalence of quadriceps tendon enthesophytes in type I $(P=0.033)$, while Infrapatellar $(P=0.023)$ and retrocalcaneal bursitis $(P=0.001)$ were more prevalent in type II DM.

Conclusions: Early evaluation of any diabetic patient regarding BMD by DEXA scan and soft tissue by MSUS seems to be beneficial for early detection of any abnormality and therefore early management and prevention of complications. References:

[1] American Diabetes Association. Diagnosis and classification of diabetes mellitus. Diabetes Care. 2013; 36

[2] Blake GM and Fogelman I. DEXA scanning and its interpretation in osteoporosis. Hosp Med 2003; 64:521-5.

[3] Balint PV, Kane D, Wilson H, Mclnnes IB and Sturrock RD: Ultrasonography of entheseal insertions in the lower limb in spondyloarthropathy. Ann Rheum Dis 2002 ; 61:905-910.

Disclosure of Interest: None declared

DOI: 10.1136/annrheumdis-2017-eular.2420

\section{AB1063 ULTRASONOGRAPHIC ASSESSMENT OF SYNOVITIS IN PATIENTS WITH LESSOR TOE DEFORMITY DUE TO RHEUMATOID ARTHRITIS}

T. Kashiwagura ${ }^{1}$, Y. Kimura ${ }^{2}$, I. Wakabayashi ${ }^{3}$, M. Fujii ${ }^{2}$, M. Kobayashi ${ }^{4}$, M. Urayama ${ }^{5}$, T. Aizawa ${ }^{6}$, Y. Sugimura ${ }^{7}$, H. Aonuma ${ }^{8}$, N. Miyakoshi ${ }^{9}$, Y. Shimada ${ }^{10} .{ }^{1}$ Department of Orthopedic Surgery, Akita City Hospital; ${ }^{2}$ Department of Orthopedic Surgery; ${ }^{3}$ Department of Rehabilitation Medicine, Akita City Hospital, Akita; ${ }^{4}$ Department of Orthopedic Surgery, Hiraka General Hospital, Yokote; ${ }^{5}$ Department of Orthopedic Surgery, Ogachi General Hospital, Yuzawa; ${ }^{6}$ Department of Orthopedic Surgery, Kita Akita Municipal Hospital, Kita Akita; ${ }^{7}$ Department of Orthopedic Surgery, Nakadori general hospital, Akita; ${ }^{8}$ Kakunodate general hospital, Senboku; ${ }^{9}$ Akita University Graduate school of Medicine, Akita, Japan; ${ }^{10}$ Department of Orthopedic Surgery, Akita University Graduate school of Medicine, Akita, Japan

Background: In recent years, joint ultrasonography has been widely used for the diagnosis and treatment of rheumatoid arthritis (RA), allowing visualization of synovitis. Its clinical usefulness in early diagnosis and evaluation of disease activity has been reported. Continuous inflammation, osteochondral destruction, and soft tissue destruction due to synovitis in toe joints result in various clinical pictures of the foot. In the lateral toes in the forefoot, subluxation or luxation of the metatarsophalangeal (MTP) joints may occur, leading to painful callosities and resultant disturbance in activities of daily living. Few reports have addressed toe deformity and joint ultrasonographic findings of synovitis in the forefoot.

Objectives: In this study, lateral MTP joints were assessed using joint ultrasonography in RA patients to examine the correlation with deformity.

Methods: Seventy feet of 61 RA patients were examined in the outpatient clinic of our hospital. Patients who underwent surgery were excluded. The mean age of the patients was 66 years (24 to 92 years), and the mean duration of disease was 12 years and 9 months ( 1 month to 40 years). Biologic products were used for 23 feet. Joint ultrasonography was performed by the same examiner, using the same room and apparatus. Synovitis was defined as Grade 1 or more as determined by the power Doppler method. Based on foot radiographs in upright position obtained before and after ultrasonography, patients with luxation, subluxation, and joint fissure narrowing were classified into the deformity group, those with bone erosion and geode formation into the bone erosion group, and lack of abnormal findings into the normal group. 